\title{
An Analysis of the Structure of Inter-Enterprise Relations Based on Knowledge Sharing in Innovation Cluster
}

\author{
Jie ZHEN ${ }^{*}$ \\ Business School, East China University of Political Science and Law, P.R. China, 201620 \\ jetzhen@163.com \\ ${ }^{*}$ Corresponding author
}

Keywords: Positionality, Knowledge sharing, Inter-enterprise relations.

\begin{abstract}
Based on the analysis of the inter-enterprise relations in innovation cluster, this paper divides the knowledge sharing patterns into four types and elaborates four positional relations among the enterprises. The different positions of the enterprises and their interaction form the structure of inter-enterprises relations. According to the density of relations, this paper divides the relational structure into centralization type and decentralization type. Then, with two dimentions of knowledge heterogeneous and knowledge gap, this paper gives a deep analysis on inter-enterprise relational structure. Besides, with two dimentions of knowledge representation and knowledge complexity, this paper analyzes the knowledge sharing level and expounds the relational structure. Finally, the paper constructs the positionality model.
\end{abstract}

\section{Inter-firm Knowledge Sharing Patterns in Innovation Cluster}

According to Hansen's theory of knowledge sharing process, a complete knowledge sharing process consists of two phases, namely knowledge-seeking phase and the knowledge-transferring phase [1]. But as for the enterprises in innovation cluster, Hansen's two-stages method does not completely reflect the process of knowledge sharing among them. Knowledge sharing between the enterprises presents as not only knowledge seeking and knowledge transfer, but also knowledge production. Knowledge has become a key economic resource, as well as the dominant source of competitive advantage, and may even be the only source (Peter f. Drucker, 1995). Based on this point, Ikujirō Nonaka(1995)articulates the knowledge transformation process in SECI (socialization, externalization, combination and internalization) knowledge transformation pattern of knowledge production and knowledge creation processes. In the enterprises cooperation network, tacit knowledge is transferred and disseminated among them, finally absorbed and sublimed through sharing, conceptualization and systemization.

It can be seen that if divided by the standard of the existing of new knowledge in inter-firm cooperation, the knowledge shared by enterprises consists of stock knowledge and incremental knowledge. Both of the two types of knowledge can be disordered(unconsciously) shared and ordered(intentionally) shared(see Figure 1).

\begin{tabular}{c|c|c|}
\multicolumn{1}{c}{} & \multicolumn{1}{c}{ Stock Knowledge } & \multicolumn{1}{c}{ Incremental Knowledge } \\
\cline { 2 - 3 } Disordered Sharing & Daily Communication & In-Depth Discussion \\
\cline { 2 - 3 } Ordered Sharing & Knowledge Base Construction & R\&D Cooperation \\
\hline
\end{tabular}

Fig. 1 The patterns of knowledge sharing among the firms in innovation cluster

\section{The Inter-firm Position Relationship of the Enterprises}

The process of knowledge sharing which takes knowledge production as the core makes the 
enterprises form a specific network, and each enterprise occupies a different position in this network. The enterprises differentially occupy the knowledge resources and allocate the knowledge resources according to their different positions in the network [2], making different contributions in the knowledge production. It is the different positions of the enterprises and the interaction between the various locations that determines the relationship between the enterprises within the cluster structure.

In the network composed of different locations, the center position of the network and the location of network hole are the most critical [3]. If the different firms can be linked by line segments, the structural holes (Burt, 1992) will then be formed when there are no lines among some of those firms.

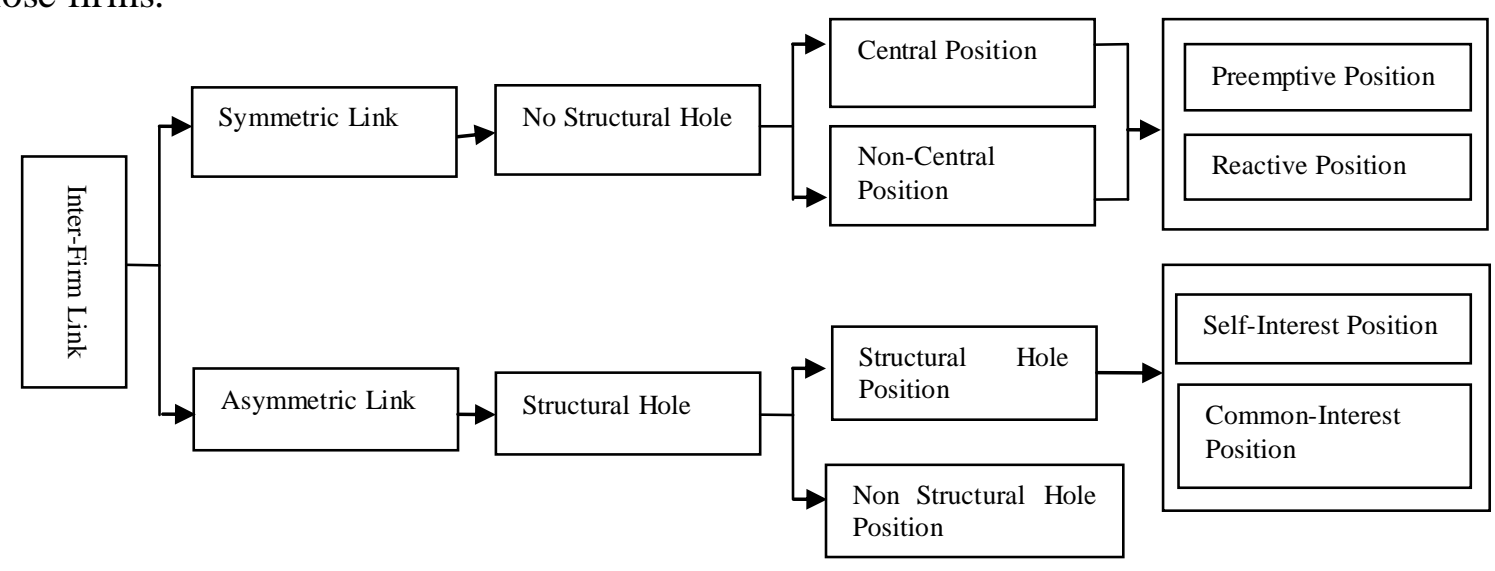

Fig. 2 The positional relations of inter-enterprise of produce service

The firm occupying the location of structural hole can possess more updated, non-repeated information and have the advantage of maintaining and controlling information [4], thus being in a more powerful position. At the same time, such enterprises also act as a bridge to increase the flow of knowledge throughout the network, improving the efficiency of knowledge sharing among enterprises.

\section{The Inter-firm Relational Structure of the Enterprises}

It is generally believed that the dimensions of inter-firm relational structure are usually embodied by the characteristics of social network, social connection and other structural elements ${ }^{[5]}$. The relationships network of the enterprises is an overall network intertwined by multiple relationships, combined by multiple local networks, evolving constantly [6], in which the density, intensity and flexibility of the relationships affect the knowledge sharing process and the evolution of the network.

\section{Density-based Inter-firm Relational Structure}

In innovation cluster, the enterprises with advantages will be in a favorable position, that is, the central location or structural hole location. In this case, the inter-firm relational structure gives the hub node some kind of leadership power in the knowledge sharing network so that it has an important status corresponding to its position. This kind of structure can be called "centralised relational structure".

In the cluster, the enterprises with geographical and locational proximity have more frequent and dense connections, showing characteristics of the so-called "community structure" [6], in which the enterprises form a "community ". The relationship between enterprises within the community has a high degree of density, while the inter-community relational density is relatively low. Therefore, this kind of community structure can be called "decentralized relationship structure".From the point of view of the whole network, the density of relationship among enterprises is not evenly distributed. Inter-firm relationship structure presents a dense feature around hub nodes of the centralized relational structure and within the community of decentralized relational structure. While around 
non-hub nodes of the centralized relational structure and in inter-community of decentralized relational structure, the inter-firm relationship structure presents a sparse one.

\section{Intensity-based Inter-firm Relational Structure}

Granovetter (1985) developed the study of "embeddedness" and proposed the concept of "relational embeddedness". According to the span of communication time, the frequency of communication, the degree of reciprocity and the depth of emotion, he distinguished the strength of the relationship so that the embedded relationship is divided into strong relationship and weak one [7]. This criterion for division of strong and weak relationships is applied to the study of industrial clusters by Uzzi (1997), and the intra-cluster transaction relations are divided into arm's length ties and embedded ties.

In a relational network, each enterprise has different knowledge in terms of quantity and quality, which can be regarded as the knowledge gap. The size of this difference can be measured by knowledge gap strength. In the case of big knowledge gap between enterprises, enterprises with strong knowledge status are at the core of the knowledge sharing process, occupying the central position or structural hole position, and the relationship structure among enterprises is also subordinate to the centralized relational structure. In the case of low intensity of knowledge gap between enterprises, enterprises are basically in symmetrical and equal status in the process of knowledge sharing, and no enterprise in the shared network is in the absolute core position. The inter-firm relational structure subordinates to the decentralized relational structure.

On the other hand, analyzing from knowledge content or knowledge relevance, inter-firm knowledge may be relevant or close to the same knowledge system; or it may also be relevant while not belonging to the same or a similar knowledge system. This phenomenon can be called the heterogeneity of knowledge, measured by the intensity of knowledge heterogeneity. When the intensity of enterprise knowledge heterogeneity is high, these enterprises are generally in different communities. The relationship between enterprises is weak, subordinating to the decentralized relational structure. Correspondingly, when the intensity of knowledge heterogeneity is low, the enterprises may subordinate to either the structure of decentralized relations or the centralized relational structure.

\section{Flexibility-based Inter-firm Relational Structure}

The flexibility of inter-firm relationships represents the ability to rapidly integrate resources across borders (Melissa A. Schilling, 2001), which allows firms to deal flexibly with inter-firm relationships through internal specialization of core business and relational integration of non-core businesses (Afuah, A., 2003).

Knowledge sharing has two effects in inter-firm relations: knowledge sharing efficiencies (KSE) and knowledge sharing synergies (KSS) (Todd Dewett, Gareth R. Jones, 2001). At the same time, knowledge itself is a complex network system, whose internal components are interconnected, nested and recursive (Ding Wei, 2006), making the enterprise relationship network as a system show the multi-level, multi-part complexity in inter-firm relationships with knowledge sharing as the core. On the other hand, knowledge can be divided into explicit knowledge and tacit knowledge (Polanyi M., 1958). Taking the complexity and degree of expression as two dimensions, we can measure the degree of inter-firm knowledge sharing difficulty within the network.

In the centralized structure, if the complexity of inter-firm knowledge sharing is low, knowledge aggregation, processing and integration are easier. The enterprises in central location or structural hole can conduct configuration and transfer of knowledge conveniently. At the same time, explicit knowledge will make it easier for the enterprises at the core position to control the other enterprises. The dominant rules of relations among enterprises are more explicit in stylized language, and strong control will become the important way to improve the inter-firm relational KSEs. At this time, the enterprises that play the role of control are at the core, and the inter-firm relational network with knowledge sharing as the core can be regarded as a nuclear relational network, which belongs to the centralized relational structure.

As the complexity of knowledge increases, the cognition of knowledge and the requirements for 
knowledge content will soon break through the capacity limit of individual enterprise, even the enterprise in the central location or structural hole will also face this situation. At this time, it is difficult for the enterprises to exert a significant impact on other related enterprises by dominating the rules. In the process of complex knowledge sharing, each enterprise has part of the relevant knowledge and information, KSS will play a greater role among enterprises. In such a development context, the conduct and guarantee of KSE requires inter-firm relational flexibility. In the meantime, the inter-firm network structure is subordinate to the decentralized relational structure.

\section{Structural Model of the Inter-enterprise Relations in Innovation Cluster}

From the point of network, the positon relations of the inter-enterprise in innovation cluster interweave together and show up the intricate form. In this network environment, the enterprises put forward demands for knowledge sharing and innovation due to their nature and conditions requirements outside the network. Meanwhile, the related knowledge from the outside environment can also be imported into the relational networks. This process can not only couple with the information input and the communication among the internal and external subjects, but be the results of initiatively external seek by the companies and other related subjects in the network. The information and knowledge input the relational network finally form the knowledge of the enterprises and the network as a whole through the selection, transfer, absorption and utilization of the network system.

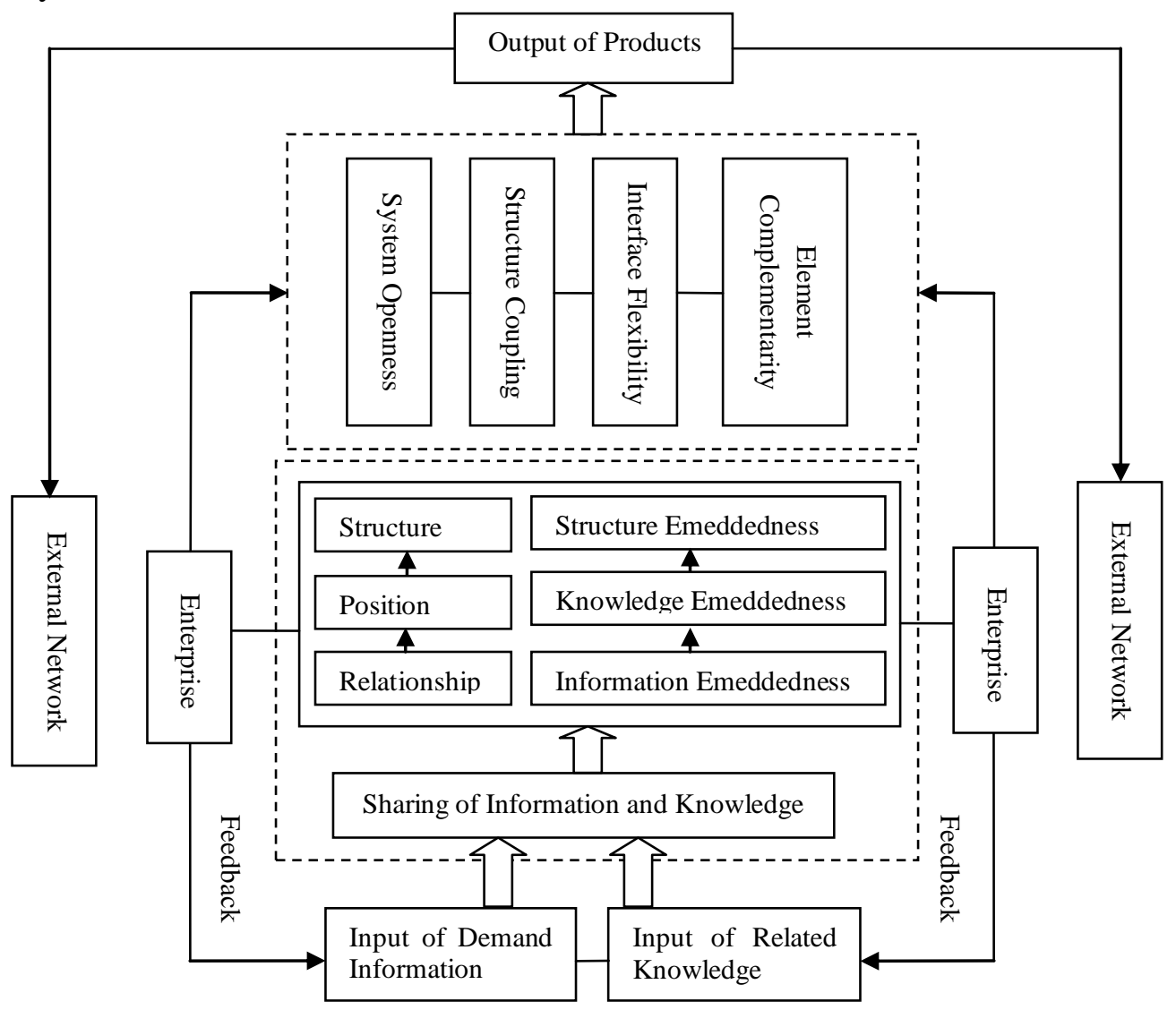

Fig.3 Structural model of inter-firm relationship in innovation cluster

After the related information and knowledge is input the network, the enterprises in the network continue step into the process of sharing the information and knowledge based on the needs of innovation. In the process, the enterprises engender various relations and adjust their positions in the network, finally form a certain concrete relational structure. Simutaneously, information embedding and knowledge embedding make the related enterprise stand at a specific positon in the network and form certain relational structure which can in turn affect the enterprise. Here, we extend the meaning of structural embeddedness and consider that structural embeddedness can also 
be a mutual coincidence in the process of knowledge interaction between enterprises through the associated interface. According to the operational process of the relational structure of the enterprises, it outstandingly manifests the characteristics of the system openness, structure coupling, interface flexibility and element complementarity. Based on the above ideas, this paper constructs the model of the inter-firm relational structure of productive service enterprises.

In fact, the knowledge sharing among the enterprises in innovation cluster is the result of the balance of self-interest of enterprises based on relational structure. Meanwhile, the knowledge sharing in equilibrium is limited to the community network, forming a highly fragmented knowledge flow network (Elisa G, Martin B, 2005). To a certain extent, knowledge resource is a kind of "club goods" [8]. It can be seen that this balance is not completely a spontaneous process, but needs appropriate mechanisms to coordinate. Therefore, further research can be carried out based on the analysis of the relational structure to explore the coordination mechanism of the enterprises.

\section{Acknowledgement}

This research was financially supported by East China University of Political Science and Law under Grant 2017 Science Research Project, Shanghai Social Sciences Planning Project under Grant 2015JG009-BGL307 and the National Social Science Foundation of China under Grant 17BGL099.

\section{References}

[1] Hansen M.T. (1999). The search-transfer problem: The role of weak ties in sharing knowledge across organization subunits[J]. Administrative Science Quarterly, 44(1): 82-111.

[2] Li Huaibin. (2008). Social embeddedness and social shaping of economic organization. China Industrial Economics,(7):16-25.

[3] Huang Zhongwei, Wang Yulu. (2008). Locational embeddedness, social capital and network learning of overseas subsidiaries in host country. China Industrial Economics, (12):144-154.

[4] Sheng Ya, Fan Dongliang.(2009). Structural holes classification theory and its application in innovation network. Studies in Science of Science, 27(9):1407-1411.

[5] Ke Jianglin, Shi Jintao. (2007). Optimizing the structure of social capital for effective knowledge transfer in knowledge team. R\&D Management, 19(1):21-28.

[6] Cai Ning, Wu Jiebing. (2006). Social network analysis on denseness of interorganizational networks in industrial clusters. Journal of Zhejiang University(Humanities and Social Sciences) ,36(7):58-65.

[7] M Granovetter.(1973). The Strength of Weak Ties. American Journal of Sociology, 78(6): 1360-1380.

[8] Wang Xiaojuan. (2008). The relationship between knowledge network and innovation perform for cluster fims: evidence from huangyan mould cluster in Zhejiang. Studies in Science of Science, 26(4):874-879. 